\title{
La construcción de la imagen pública del poder a través del protocolo y el ceremonial. Referencias históricas
}

\author{
Olga CASAl Maceiras \\ Universidad de Vigo \\ olga.casal@yahoo.es
}

\begin{abstract}
Resumen
Protocolo y ceremonial están presentes en todas las etapas de la historia de la humanidad actuando como instrumentos de comunicación no verbal que transmiten mensajes de jerarquía y poder a sus destinatarios sociales. Desde la antigüedad encontramos referencias a los ritos ceremoniales que relatan acontecimientos de la vida social, especialmente los que tienen un carácter simbólico, honorífico o conmemorativo, como las entradas triunfales de los soberanos en las ciudades, las ceremonias de coronación o investidura, las bodas y exequias de los miembros de familias reales o los desfiles militares.
\end{abstract}

Palabras clave: Protocolo; Ceremonial; Comunicación; Imagen Pública; Historia

The construction of the public image of power through the protocol and ceremonial. Historical references

\begin{abstract}
Protocol and ceremonial are present at all stages of the history of mankind, acting as instruments of nonverbal communication that convey messages of hierarchy and social power to their recipients. Since ancient times we find references to the ceremonial rites that relate social life events, especially those with a symbolic, honorary or memorial, and triumphal entries of rulers in the cities, the coronation or inauguration ceremonies, weddings and funerals of members of royal families and military parades.
\end{abstract}

Key words: Protocol; Ceremonial; Communication; Public Image; History

\section{Referencia normalizada:}

Casal Maceiras, O. (2013) La construcción de la imagen pública del poder a través del protocolo y el ceremonial. Referencias históricas. Historia y Comunicación Social. Vol. 18 № Especial Octubre. Págs. 761-775.

Sumario: 1. Introducción. 2. Edad Antigua. 3. Edad Media. 4. Edad Moderna. 5. Edad Contemporánea. 6. Conclusiones. 7. Bibliografía 


\section{Introducción}

Protocolo y ceremonial están presentes en todas las etapas de la historia de la humanidad actuando como instrumentos de comunicación no verbal que transmiten mensajes de jerarquía y poder a sus destinatarios sociales.

Desde la antigüedad encontramos referencias a los ritos que relatan acontecimientos de la vida social, especialmente los que tienen un carácter simbólico, honorífico o conmemorativo. Se trata de manifestaciones públicas del poder establecido, como las entradas triunfales de los soberanos en las ciudades, las ceremonias de coronación o investidura, las bodas y exequias de los miembros de familias reales o los desfiles militares. Acontecimientos extraordinarios, todos ellos, que dan visibilidad a las instituciones conectándolas con el pueblo a través de la celebración de ceremonias públicas.

Esta práctica se convierte en una constante a lo largo de la historia, y sigue vigente hasta nuestros días, en todas las culturas y sistemas políticos conocidos, lo cual es signo inequívoco de su eficacia comunicativa. "Gobernar es aparentar", decía Napoleón, consciente de que "el pueblo no lee los decretos, pero ve los actos".

Como señalan varios autores -Marín Calahorro (1997), Ramos (2003), Otero $(2009,2011)$ y Vilarrubias $(2000,2004)$, entre otros- el protocolo se convierte así en la principal herramienta de comunicación no verbal entre las organizaciones y sus públicos, codificando el mensaje institucional a través de elementos cargados de simbolismo y actuando como un instrumento de ordenación. Personas, espacios y secuencias temporales son ordenadas de una manera determinada y concreta en función de las circunstancias que rodean al acto, con el objetivo último de escenificar el mensaje de la organización convocante.

\section{Edad Antigua}

El protocolo y el ceremonial nacen con la sociedad misma, cuando los individuos se organizan en grupos y necesitan herramientas de convivencia pacífica y exaltación de las posiciones hegemónicas.

Una constante histórica, desde tiempos remotos hasta la Edad Moderna, es la convicción sobre el origen divino de las leyes, que las instancias más altas del poder pretenden comunicar de manera simbólica a sus súbditos. Encontramos el primer ejemplo en la antigua Mesopotamia, donde el Código de Hammurabi (1793-1749 a.C.), representa al dios Shamash entregando las leyes al rey Hammurabi. Además de ser el código jurídico más antiguo de la humanidad, es también el primer documento conocido que incorpora algunas pautas de puro protocolo, como la ceremonia de coronación del rey, una ordenación de precedencias y una serie de recomendaciones dirigidas a los funcionarios instándoles a que extremen el cuidado en la realización de las ceremonias institucionales. 
También Egipto participa de esta creencia y vincula el poder político al religioso, poniendo en práctica sofisticados ritos ceremoniales en torno a la corte del faraón, que encarna la doble condición de dios y monarca. A través de antiguos textos conocemos los detalles de la ceremonia de coronación, los ritos fúnebres, las conmemoraciones militares o la recepción de embajadores extranjeros. Asimismo, dan cuenta del rígido orden que imperaba en la vida diaria del soberano, dirigida y coordinada por altos funcionarios y sacerdotes (Otero, 2009).

En la China imperial existía un Tribunal de Ritos, integrado por mandarines y letrados, cuya misión era organizar las ceremonias públicas, cortesanas o religiosas. Durante cinco siglos se impuso además un estricto protocolo que no permitió la entrada de los súbditos en la Ciudad Púrpura Prohibida, donde vivieron veinticuatro emperadores, hasta 1911, alejados de la vida de su pueblo.

Este código proxémico que administra las distancias entre los súbditos y su soberano, se repite en diversos contextos históricos, como el Imperio Romano, cuando el emperador Diocleciano fue implementando un sofisticado ceremonial de acceso a su real persona que dificultaba que incluso sus más próximos pudieran acercarse a él. Ocurrirá lo mismo en la corte española, con la incorporación del protocolo de Borgoña, como veremos más adelante.

Sorprendentemente, nada del boato de estas antiguas civilizaciones aparece en Grecia, donde la convivencia social se desarrolla de una forma más sencilla. Las relaciones con otros pueblos, sin embargo, fue una preocupación constante en la Grecia clásica, por lo que los griegos articulan una rigurosa reglamentación que garantiza la inviolabilidad de los embajadores extranjeros, al mismo tiempo que se nombraban cónsules para proteger los derechos de los ciudadanos fuera de su polis. Aquí está la base de las actuales relaciones diplomáticas.

El Imperio Romano, en su época de mayor esplendor, domina todo el mundo civilizado y lo romaniza, es decir, exporta e impone su organización sociopolítica, económica y cultural en aquellos territorios que ocupa. Y como parte de su idiosincrasia, también exporta sus ritos y ceremonias.

Las apariciones públicas de los emperadores romanos contienen una importante carga simbólica y comunicativa. Prestan especial atención a las ceremonias institucionales, los espectáculos y cualquier ocasión en que el soberano se presenta ante sus súbditos, rentabilizándolas como una forma de propaganda a través de la visibilidad. El objetivo es evidenciar el poder.

La ceremonia del triunfo romana, por ejemplo, que tendrá continuidad en la Europa medieval, tiene su origen en la simbiosis inextricable entre las fiestas religiosas y las profanas. El caudillo entraba triunfante en la ciudad al frente de sus tropas, que desfilaban solemnemente custodiando el botín de guerra y a los prisioneros. Atravesaban la puerta de triunfo en un acto ritual por el que el ejército se purificaba de las culpas de sangre perpetradas en la guerra, concluyendo el desfile en el Capitolio, donde el caudillo victorioso ofrecía a los dioses los sacrificios (Monteagudo, 1995). 
Pero a medida que Roma se va expandiendo, convirtiéndose en una potencia mundial, la política y religión se distancian, y desde finales del siglo II el triunfo se va convirtiendo en un medio de ostentación personal a través de la cual el ejército y sus caudillos pretenden ganarse la simpatía popular. Por extensión, estas ceremonias de llegada se realizan también para conmemorar la entrada de los emperadores en la Ciudad Eterna.

En Bizancio, el emperador Constantino permitió al cristianismo salir de la clandestinidad tras promulgar el Edicto de Milán en 313, lo que trajo como resultado la expansión de la Iglesia. Desde entonces, los emperadores empiezan a identificarse con la divinidad cristiana y, como consecuencia de ello, el ceremonial de la corte imperial se va volviendo magnificente y sofisticado, intentando resaltar el carácter divino del monarca.

Con la desmembración del Imperio Romano, desaparece la actividad diplomática como elemento del ceremonial público. Sólo el Imperio Bizantino, que sigue practicándolo en la corte imperial, y el Papado, que lo desarrolla en los actos litúrgicos como lenguaje simbólico de exaltación religiosa, continúan practicándolo (Otero, 2009).

\section{Edad Media}

La etapa medieval nos trae como novedad el ceremonial de la coronación, inaugurado por el Imperio Carolingio en el siglo $\mathrm{V}$ y con enorme repercusión en épocas posteriores.

La primera coronación que se conoce es la del rey franco Clovis, en el año 496, uncido con la Santa Ampulla, que contenía el santo óleo. Ésta se convertiría a partir de entonces en instrumento fundamental, marcando el carácter sagrado de la monarquía (Monteagudo, 1995).

Carlomagno instala su corte en Aix-la-Chapelle, donde decide crear un auténtico centro intelectual, político, artístico y administrativo, por lo que empieza a prestar atención al ceremonial heredado de Bizancio como elemento simbólico del poder (Otero, 2009).

La ceremonia de su coronación fue, en sí misma, un acto de exaltación de su persona, que comienza cuando el día de Navidad del año 800 entra en Roma con honores de emperador romano y el papa León III oficia la misa en la que se celebra la ceremonia de la coronación imperial. Al recibir la corona de manos del propio papa, Carlomagno afirmaba simbólicamente no sólo su propio poder sino también el origen divino del mismo.

A los actos de unción y coronación se unió el de la aclamación, tercer elemento del ritual, que consistía en la conformidad de los presentes expresada por medio de 
exclamaciones, a la manera bizantina. Pero aquí observamos una sutil diferencia: mientras que en Bizancio la aclamación pública constituía el acto de elección misma al realizarse antes de la coronación, en la ceremonia de Carlomagno el papa cambió el orden de los actos, programando la aclamación al final y realzando con ello la importancia de la coronación y, por tanto, su propio protagonismo. A la aclamación popular siguió la eclesiástica, y a continuación, el propio papa le rendiría homenaje. Por tanto, no sólo los actos de coronación transmiten un mensaje de poder por sí mismos, sino que el propio orden de las secuencias en que se desarrollan también aporta un significado y sienta un precedente.

Tras la caída del Imperio Romano, los visigodos se instalan en la Península Ibérica. La cultura visigoda, fuertemente impregnada de la tradición romana, estaba, no obstante, al servicio de la religión cristiana, que había adoptado en el año 589 tras renunciar al arrianismo. Según Otero (2009: 84), a partir de entonces "la identificación de la Iglesia Católica con el poder del Estado es absoluta y se inicia la prácticamente imperecedera alianza altar-trono (...)".

Con la llegada de los musulmanes a la Península Ibérica, se produce una ruptura con la tradición romana y visigoda, tanto en la lengua, como en la religión y en las costumbres. Sin embargo, y a pesar de las diferencias culturales, la importancia que los soberanos de Al-Andalus otorgan a las apariciones públicas y a los símbolos como manifestaciones externas de su poder es idéntica a las culturas precedentes (Otero 2009). Estos símbolos se materializan en la ceremonia de investidura, que sigue el modelo oriental de prestar juramento de fidelidad al soberano con un besamanos que podía durar varios días y tenía lugar en el alcázar o en la entrada de la mezquita mayor. También la utilización del trono durante las recepciones constituía un símbolo de poder, igual que los distintivos de la soberanía, como el turbante que portaba el monarca (hasta el siglo X los reyes no utilizarán la corona), el cetro de bambú, el sello real que se le entregaba al acceder al trono y un quitasol a modo de palio que utilizaba en las campañas militares (Fernández de Córdova, 2002).

Durante el siglo X, se abandona el sistema de monarquía electiva de los visigodos y comienza la sucesión hereditaria basada en la primogenitura. Martínez Sánchez (2008) sostiene que los reyes, para asegurar la sucesión de sus herederos, intentan que sean reconocidos anticipadamente por el pueblo, los nobles y la Iglesia, haciéndoles jurar fidelidad y obediencia ante estos, y afirma que aquí reside precisamente el origen de la jura de los príncipes en España, que se ha mantenido hasta hoy.

Por otra parte, el rito de acceso al trono se configura como el más relevante de todo el ceremonial regio, por lo que parece revelar sobre el origen del poder y las relaciones del rey con sus súbditos (Río Barredo, 1998), si bien se manifestará de manera distinta en los diferentes territorios de la Península Ibérica, conformada en esta época por un conjunto de reinos con tradiciones y costumbres propias, como veremos a continuación.

En el reino de Castilla y León no existe una normativa específica que regule el ceremonial, pero se conmemoran acontecimientos, como funerales o bodas, que 
contribuyen a crear una conciencia colectiva de pertenencia a una colectividad determinada. Otero (2009: 87) atribuye este hecho a la necesidad que la monarquía tiene de "crear una imagen de Estado", con el objeto de escenificar la superioridad y el origen divino del poder real.

En cuanto al acceso al trono y la manera de hacerlo público, la imposición de la corona se produce de forma variable, ya que unos reyes son entronizados y otros aclamados (Orcástegui, 1995), pero no son uncidos. Monteagudo (1995) sostiene que la realeza castellana estaba más unida a los ideales militares -por su trayectoria de reconquista- que a los sagrados, por lo que los ritos de entronización tenían en Castilla un sesgo más secular, basado en un intercambio de juramentos entre el rey y las Cortes. En este contexto, tenía especial relevancia la ceremonia de armarse caballero, ritual laico en el que el propio rey se autoimponía la espada. De esta manera se hacía patente que recibía su autoridad directamente de Dios y sin dependencia de la Iglesia, si bien la espada había sido bendecida previamente por el obispo, a fin de asegurarse también la legitimidad religiosa (Nieto, 2007). El hecho mismo de celebrar la ceremonia en la catedral indica la intención de asociar la imagen del máximo representante del poder político con la divinidad. El ceremonial se completaba con el alzamiento de pendones al grito de "Castilla por el rey", de tradición visigoda, y el besamanos, heredado de las costumbres musulmanas.

A diferencia de Castilla, el reino de Aragón es deudor de su estrecho vínculo con la Santa Sede y desde el siglo XI establece un ceremonial que recibe la influencia de las coronaciones imperiales de los papas. Sin embargo, será con Alfonso IV cuando los reyes aragoneses abandonarán la liturgia del pontifical romano para introducir un ceremonial de coronación propio y genuino.

En 1328, en la seo de El Salvador de Zaragoza, se produce un hecho insólito cuando el rey, ungido con óleo por el prelado, actúa como ministro de la celebración y, en la ceremonia de investidura, él mismo toma la espada del altar, ofreciéndose con ella a Dios y armándose caballero. En una segunda ceremonia, el rey toma la corona del altar y se la pone con sus propias manos, aunque ayudado por el prelado y los infantes. A continuación, coge también con sus propias manos la espada, el cetro y el globo, distintivos de su autoridad y poder. La autoinvestidura y la autocoronación constituyen una novedad que quedará instaurada desde entonces en el ceremonial de los reyes aragoneses y será imitada más adelante por otras monarquías (Durán, 1989; Orcástegui, 1995). Así, desde el reinado de Alfonso IV quedó claro que ni la unción ni la coronación eran los transmisores del poder real, sino que éste se heredaba a la muerte del rey predecesor por derecho de sucesión. Como consecuencia, el símbolo principal del poder regio dejó de ser la corona para pasar a ser la espada, que se convirtió en Aragón -como ya lo era en Castilla- en un símbolo de independencia y soberanía real sobre los territorios conquistados en campañas militares.

En 1336 Pedro IV el Ceremonioso se ajustó al modelo fijado por su padre y predecesor, pero introdujo también novedades inspiradas en el nuevo espíritu de exaltación y afirmación monárquica: en la ceremonia de coronación no permitió que nadie 
tocara la corona, salvo él mismo, que se la colocó sobre su cabeza sin ayuda de nadie, tomando a continuación el cetro, el anillo y el pomo imperial, dejando al arzobispo únicamente el papel de los rezos. Él mismo coronó también a la reina. Finalizada la misa, el rey juró a los aragoneses sus fueros y privilegios, sin esperar a tener Cortes del reino, como había hecho su padre.

Basándose en este ceremonial, el antiguo pontifical romano de Huesca y los ritos inaugurados por Alfonso IV, Pedro el Ceremonioso mandó redactar en 1353 un riguroso ritual de coronación del rey y de la reina que habría de perdurar hasta el siglo $\mathrm{XV}$, cuando los reyes consideran que su poder se apoya en el derecho hereditario, lo que hará innecesaria la unción (Monteagudo, 1995).

Más allá de los Pirineos, el pequeño ducado de Borgoña era en los siglos XIV y XV un territorio vasallo del rey de Francia. Nunca fue una gran potencia en el contexto político y militar de las cortes europeas, pero este hecho quedaba contrarrestado al destacar por los brillantes fastos de ceremonial y etiqueta que rodeaban a su corte. Desde las audiencias, en las que el duque aparecía sentado en un trono elevado ante sus súbditos rigurosamente organizados por jerarquías, hasta las comidas, en las que sus servidores asumían unas funciones estrictamente reguladas y ordenadas, con una severidad casi litúrgica que semejaba un espectáculo, rodeaba al monarca de un aura casi divina (Rodríguez Ennes, 2003). El estricto ritual en torno al soberano favorecía la idea de su superioridad sobre sus súbditos, al tiempo que homogeneizaba y cohesionaba con ello los territorios sobre los que ejercía el poder.

\section{Edad Moderna}

La necesidad legitimadora del poder es una constante en la historia y varios autores (Fernández de Córdova, 2002, 2007; Nieto, 1999; Otero, 2009) identifican en las monarquías una relación directa entre actividad propagandística y legitimación política, como ocurre en el caso de los Reyes Católicos, cuyo poder nace en la crisis sucesoria de Enrique IV y acusa una imperiosa necesidad de autoafirmación.

Celebraciones litúrgicas de acción de gracias, procesiones y desfiles triunfales se convirtieron en instrumentos de propaganda ceremonial durante su reinado, igual que la celebración de las bodas y bautizos de los infantes, la investidura de caballeros o la concesión de dignidades, poniendo el énfasis en el espectáculo monárquico, que transformaba así el "ritual cortesano" en "ritual dinástico", como indica Fernández de Córdova (2004, 2007).

La corte es el lugar donde se escenifica el poder regio como expresión de sus necesidades propagandísticas. Una de las principales funciones de los usos cortesanos era, según afirma Fernández de Córdova (2004: 55), "el de definir las distancias, delimitar los espacios, o establecer los signos y gestos que debían corresponder a las diferentes dignidades (...)", cosa que los Reyes Católicos hicieron de manera consciente y deliberada, como demuestra el uso del cetro por parte de Isabel y la espada 
por Fernando, la utilización de un trono más bajo en el caso de la reina, la cesión de la palabra en las audiencias, o la entrega del portapaz en las ceremonias de la Capilla. Los reyes exigían además que los nobles saludaran con un besamanos, reverencias y con la cabeza descubierta, y todo ello en un espacio cuidadosamente preparado para garantizar la separación del rey mediante estrados, palios, doseles y cortinas, que alejase cualquier idea de familiaridad.

Durante la Edad Moderna se registra en España uno de los grandes hitos del ceremonial, con la incorporación del protocolo de Borgoña. La estricta etiqueta que imperaba en el ducado borgoñón desde mediados del siglo XIV llega a España por primera vez con motivo de un banquete ofrecido por Felipe el Hermoso, heredero del ducado, a su esposa doña Juana y los padres de ésta, los Reyes Católicos. La gran novedad del acontecimiento fue la introducción del ceremonial borgoñón, que asignaba un servidor para cada comensal y dotaba a la comida de un ritmo cadencioso y ritualizado, atento a todos los detalles, en contraposición al desorden habitual en la corte castellana, todo lo cual causó entre los asistentes una gran impresión (Otero, 2009).

Cuando llegó la hora de formar al príncipe Felipe, el emperador Carlos decidió que debía educar a su hijo en el uso de Borgoña, sofisticado y fastuoso, para que causara la mejor impresión en su recorrido de presentación por los Países Bajos, utilizando el protocolo como arma política.

Lisón (1992) demuestra que todo el ceremonial y el protocolo borgoñón conforma un lenguaje no verbal orientado a resaltar la figura del monarca. Tomando como ejemplo la entrada a una ciudad o a la Capilla Real, vemos cómo el soberano ocupa un lugar único y central, diferenciado y destacado con respecto a su comitiva e incluso a la reina, dejando claro quién es quién y el lugar que ocupa cada uno. Lo mismo ocurre cuando el acto tiene lugar en uno de los salones de la corte: el rey siempre ocupará el lugar central o bien el punto focal de la perspectiva, destacado por cortinas, alfombras, estrados y sillones. Se enfatiza la figura regia con un lenguaje simbólico que queda reflejado en el uso de los espacios. La separación de las aulas en el Palacio de El Escorial, cuya importancia aumenta según su grado de proximidad al soberano nos habla de un código proxémico que permite inferir que a mayor penetración de una persona en los aposentos reales, mayor será su posición jerárquica en la corte. Esta distribución espacial sigue vigente en las salas del Palacio Real y en todo el ceremonial de Estado, lo que pone de manifiesto que el poder también se escenifica en el espacio.

Pero fue el propio Felipe II, abrumado por las exigencias del protocolo borgoñón, quien introdujo los primeros cambios. A partir de su reinado, se incorpora un carácter marcadamente religioso al ceremonial real español, de manera que la mayoría de las apariciones públicas del soberano estaban motivadas por celebraciones religiosas, como reflejo de la piedad personal de los monarcas, pero también para subrayar la estrecha relación entre la monarquía y Dios, al tiempo que servía de refuerzo ideológico al pueblo, que se sentía constantemente amenazado por el islam, el judaísmo y el protestantismo. 
Durante el reinado de Felipe IV la etiqueta llegó a su punto álgido con la creación de la figura del Conductor de Embajadores, inspirada en la del Maître d'hôtel du Roi (Maestro de Ceremonias) de Enrique II de Francia, alto dignatario de su corte designado para hacer los honores a los embajadores extranjeros que llegaban a Francia. En España, el rey Felipe IV incorpora esta figura y el ceremonial que corresponde a su cometido. Este cargo, que se mantiene hasta nuestros días, es el más antiguo de la administración española.

Con la llegada de los Borbones se registran algunos cambios. Felipe V (17001746) modernizó el sistema de administración del Estado y estableció unas normas de protocolo relativas a la recepción de embajadores extranjeros que, modificadas y actualizadas por Carlos III, aún siguen vigentes, como se puede comprobar en las ceremonias de entrega de cartas credenciales que hoy en día se siguen realizando en el Palacio Real de Madrid.

Pero con Carlos III se producen nuevos cambios en el ámbito del protocolo, ya que a él se le atribuyen la creación de la bandera de España y el himno nacional.

En el siglo XVII el centro del poder europeo se localiza en Versalles, donde la corte de Luis XIV es el símbolo del Estado absoluto. Allí se definen la etiqueta, el ceremonial y las relaciones jerárquicas. El Rey Sol estableció unas complejas reglas de protocolo transformando todos los actos, incluso los más cotidianos, en un ceremonial casi sagrado, en el que el fasto tenía una función política, con lo que pretendía impresionar a los embajadores extranjeros como a su propio pueblo.

\section{Edad Contemporánea}

La Edad Contemporánea recoge las tradiciones históricas para adaptarlas a los nuevos tiempos.

Napoleón Bonaparte, por ejemplo, recupera la filosofía política del fasto propia de Luis XIV y la aplica a la ceremonia de su coronación, en la que sigue la tradición procedente del reino de Aragón tomando la corona de manos del obispo para autoimponérsela y, a continuación, coronar a su esposa. De esta manera, el emperador pretende simbolizar que es consagrado por la gracia de Dios, pero el poder que le confiere la coronación proviene de manos del pueblo. Asimismo, aunque intenta desvincularse del aura monárquica de los Borbones que le precedieron, retoma el ceremonial regio y los símbolos propios de la monarquía, como el cetro y la corona.

Napoleón promulga el que Otero (2009: 95) considera "el primer texto de protocolo moderno: el Decreto de 13 de julio de 1804" sobre las prelaciones y la etiqueta imperial, que recoge por primera vez una ordenación de precedencias del Estado, al tiempo que define los honores militares, civiles y fúnebres que se deben rendir a ciertas autoridades. 
Tras derrotar a Napoleón, las principales potencias europeas se reúnen entre 1814 y 1815 en el Congreso de Viena, que fue la primera conferencia de paz moderna, sino que reguló las relaciones diplomáticas sobre el fundamento que reconoce la igualdad de todos los Estados en las relaciones internacionales, con independencia de su capacidad económica, el tamaño de su territorio o su nivel de desarrollo. Esa igualdad jurídica se traslada también a los jefes de Estado, presidentes y monarcas de cada una de las naciones.

Desde antiguo, las precedencias generaban fricciones entre los Estados y sus representantes. Para solventarlas, el Marqués de Pombal (1760) había propuesto la ordenación de los embajadores siguiendo la fecha de sus acreditaciones. Esta idea, desechada en su momento, fue adoptada por el Congreso de Viena en 1815 para establecer un estatuto general de precedencias entre los Estados. Desde entonces, los agentes diplomáticos se ordenan según la fecha en que hubieran presentado sus credenciales ante el país de acogida, aunque siempre reservando el primer lugar de la escala para el nuncio pontificio (Otero, 2009; Ramos, 2010).

En España, durante la invasión francesa, y tras la abdicación de los Borbones, el pueblo español se negó a reconocer la autoridad de José Bonaparte, por lo que se produjo un vacío de poder que fue cubierto por las Juntas Provinciales. Estas asumieron la soberanía y se unieron en 1808 formando una Junta Central como máximo órgano de gobierno. En 1810 esta Junta Central convoca en Cádiz las Cortes extraordinarias (extraordinarias porque, por primera vez, no eran convocadas por el rey) en las que se promulgaron los decretos que sentarían las bases del Estado de Derecho. Estos nuevos principios políticos necesitaban ser escenificados en las ceremonias públicas, por lo que empiezan a tomar forma propia los actos realizados en el entorno parlamentario, como las ceremonias de apertura, jura de Constitución, la llegada al trono del monarca, su mayoría de edad o las juras del príncipe o princesa de Asturias.

Sin embargo, las Cortes de Cádiz no otorgan importancia a las precedencias, excepto para el presidente, vicepresidente, los dos secretarios y el vicesecretario. Los diputados ni siquiera tenían un escaño asignado, para simbolizar la igualdad entre todos ellos, y únicamente se reservaba al presidente una posición de preminencia en el centro de la sala (Sánchez González, 2012).

El ceremonial parlamentario iniciado en las Cortes de Cádiz ha llegado hasta nuestros días, como podemos observar en las tomas de posesión de los cargos públicos con la presencia del crucifijo y los evangelios, compartiendo mesa con el texto Constitucional.

Durante el reinado de Isabel II (1843-1868) se publican varias disposiciones importantes en cuanto al interés protocolario se refiere, ya que regulan la disposición de las autoridades y las corporaciones durante los actos públicos, así como el orden de precedencias en las recepciones oficiales que se celebran en el Salón del Trono del Palacio Real. 
Desde el fin de la Primera República hasta el comienzo de la Segunda, el 14 de abril de 1931, tiene lugar un período de estabilidad institucional en el que se restablece la monarquía. Alfonso XIII (1902-1931), inaugura el siglo XX registrando uno de los períodos más importantes del protocolo español, durante el cual se regula el uso de la bandera y el himno nacional. Pero además, también hay novedades en cuanto a la ordenación en los actos, ya que se publica una Real Orden que fijará la precedencia indicada para la entrada en las dependencias reales y el desfile ante el rey, heredera de las Etiquetas que José Bonaparte había publicado en 1809. Otero (2009) define esta norma alfonsina como la última "etiqueta de corte" y destaca su intención de ordenar y mezclar en el entorno cortesano los antiguos estamentos y las nuevas clases políticas y funcionariales, integrando en una sola lista de precedencias a todas las categorías sociales, políticas, militares, administrativas y religiosas de la nación. La importancia de los distintos grupos con acceso a las salas de palacio queda representada por la proximidad a la cámara real, tal y como se había hecho desde la antigüedad. La proxemia, una vez más, se revela como un lenguaje no verbal con un rico significado comunicativo.

Durante el Directorio Militar de Miguel Primo de Rivera se promulga una norma que recoge por primera vez en la lista de precedencias lo que denominaríamos hoy las fuerzas sociales, del mundo de la cultura o de la sociedad civil. En esta norma destaca la capacidad de la Administración para ordenarse a sí misma departamentalmente, con lo que aparece el tercer criterio de ordenación de precedencias que más tarde recogerá el Real Decreto 2099/1983, el criterio departamental, además del colegiado y el personal (Otero 2009).

Durante la II República se produce una ruptura con el Antiguo Régimen y las normas protocolarias existentes. Se cambia el himno, la bandera y el escudo y se revocan gran cantidad de títulos nobiliarios, además de las Órdenes de Caballería.

Culminada la Guerra Civil en 1939 comienza una larga etapa en la historia de España en la que el general Franco asume todos los poderes en una dictadura que se prolongaría durante cuarenta años. Desde el primer momento, el gobierno franquista restituye todas las disposiciones vigentes en la monarquía que habían sido abolidas durante la República. En este período se publica una disposición protocolaria que marcó un hito excepcional en la legislación española: el Decreto 1483/1968 de 27 de junio, por el que se aprueba el Reglamento de precedencias y ordenación de autoridades y corporaciones. Fue la primera norma que sistematizó con criterio general y uniforme la clasificación de los actos y la ordenación y prelación de las distintas autoridades y corporaciones. Básicamente, pretendía resolver los tres grandes obstáculos que se plantean en un orden de precedencias: la clasificación de los actos, la presidencia y la ordenación de los asistentes, por la necesidad de conocer, identificar y ordenar las fuerzas políticas, económicas y sociales, como ocurre en todas las sociedades culturalmente avanzadas, donde el protocolo es una herramienta del poder y del Estado (Otero 2009). 
Tras el fallecimiento del general Franco en 1975, España sufre una convulsión política y social que se materializa en el tránsito de la dictadura a la democracia. Los cambios se suceden con enorme rapidez: se restablece la monarquía, Juan Carlos I jura su cargo como Jefe del Estado, la estructura estatal se modifica con la división de poderes y aparecen nuevos cargos, autoridades e instituciones. Se producen las primeras elecciones democráticas en 1977 y se aprueba el texto constitucional en 1978, pero la norma protocolaria vigente sigue siendo el Decreto 1483/1968, de difícil aplicación ante este nuevo panorama sociopolítico al que se suma la recién estrenada organización territorial del Estado de las Autonomías.

Todo ello plantea la necesidad de regular la ordenación de precedencias en los actos oficiales. Se promulga entonces, durante el gobierno de Felipe González, el Real Decreto 2099/1983 por el que se aprueba el ordenamiento general de precedencias en el Estado (R.D.), norma protocolaria que continúa vigente en la actualidad.

Una de las grandes aportaciones de este ordenamiento es la consideración de las Comunidades Autónomas. El R.D. define dos precedencias diferentes, en función de su aplicación en actos celebrados en Madrid, como capital de España y sede de las instituciones generales del Estado, o en el resto de las autonomías. De este modo, se resalta la prelación, la simbología y el mensaje de las autoridades autonómicas sobre las autoridades del Estado (Martínez Correcher, 2002).

Esta ordenación diferenciada pone de relieve, una vez más, la importancia de las precedencias en la escenificación del poder que supone el ceremonial en los actos públicos, dando protagonismo a unas autoridades sobre otras en función del acto y la demarcación territorial donde se celebre.

Otra disposición de gran importancia en la etapa democrática fue el Real Decreto 834/1984, de 11 de abril, por el que se aprueba el Reglamento de Honores Militares, relativo a los honores a la bandera de España, a los miembros de la familia real, autoridades militares, representantes diplomáticos, honores fúnebres etc. Esta disposición permaneció vigente hasta el año 2010, cuando fue sustituida por el R.D. 684/2010, que simplifica los honores militares, sin que ello suponga una pérdida de los elementos tradicionales del Reglamento anterior.

Aunque el Estado es el mayor productor de normas protocolarias, también otras entidades territoriales emiten su propia normativa, de aplicación exclusiva dentro del marco de su competencia y su territorio, como son las comunidades autónomas y las corporaciones locales (Diputaciones provinciales, Cabildos, Consejos insulares y Ayuntamientos).

Todas las comunidades autónomas han dictado normas para regular sus símbolos de identidad, como son la bandera, el escudo y el himno, y algunas también han publicado su propia ordenación de la prelación de autoridades. También las instituciones locales tienen en su mayoría alguna normativa de honores y distinciones.

En la España actual, igual que ocurre en el resto del mundo, tanto las altas instituciones del Estado como las entidades autonómicas o locales siguen utilizando los 
acontecimientos especiales como instrumentos de proyección de su identidad ante sus destinatarios sociales. Así, la proclamación del rey, las tomas de posesión de los cargos públicos, las bodas reales que se han sucedido durante el siglo XX, la conmemoración anual del día de la Constitución o de las Fuerzas Armadas, entre otros, se convierten en transmisores del mensaje institucional que llega a los ciudadanos amplificado por los medios de comunicación social.

\section{Conclusiones}

Como hemos visto en estas páginas, todas las civilizaciones y culturas a lo largo de la historia han utilizado este rico y complejo lenguaje no verbal que son el protocolo y el ceremonial para explicitarse ante sus públicos.

El estado, el poder, las instituciones son entidades intangibles que necesitan tomar cuerpo, hacerse visibles ante los ciudadanos, para poder ser percibidas, aceptadas y legitimadas. Por eso las altas instancias del poder buscan la conexión con sus actores sociales a través de las celebraciones públicas, que actúan como vehículo transmisor de su identidad y de su mensaje, coadyuvando en la construcción de su imagen pública. Los actos, los eventos, los acontecimientos especiales son el canal a través del cual una organización, entidad emisora de la comunicación, se pone en contacto con la comunidad, receptora y destinataria de su mensaje de poder e identidad.

\section{Bibliografía}

DURÁN GUDIOL, A. (1989): "El rito de la coronación del rey en Aragón". Argensola: Revista De Ciencias Sociales Del Instituto De Estudios Altoaragoneses, (103), p. 17-40.

FERNÁNDEZ DE CÓRDOVA MIRALLES, Á. (2002): La corte de Isabel I. Ritos y ceremonias de una reina (1474-1504). Madrid: Dyckinson

(2004): "Sociedad cortesana y entorno regio". Medievalismo: Boletín De La Sociedad Española De Estudios Medievales, p. 13-14, 49-78. Disponible en: http://goo. $\mathrm{gl} / \mathrm{m} 0 \mathrm{NNxc}[28 / 08 / 2013]$

(2007): "Reyes católicos": Mutaciones y permanencias de un paradigma político en la Roma del Renacimiento. Roma y España un crisol de la cultura europea en la Edad Moderna. Actas Del Congreso Internacional. Roma. Vol. 1, Roma, p. 133-154.

LISÓN TOLOSANA, C. (1992): La imagen del rey (monarquía, realeza y poder ritual en la casa de los Austrias). Madrid: Espasa Calpe

LÓPEZ NIETO Y MALLO, F. (2006): Honores y protocolo ( $3^{\mathrm{a}}$ ed.). Madrid: Wolters Klugel España 
MARTÍNEZ CORRECHER, J. (1995): “Origen del protocolo en España”. Revista Internacional De Protocolo, (1), p. 74-75.

(1998): "Prólogo a la primera edición". En Felio Vilarrubias (Autor), Protocolo, ceremonial y heráldica en las corporaciones públicas y las empresas. ( $2^{\mathrm{a}} \mathrm{ed}$.). Oviedo: Servicio de publicaciones de la Universidad de Oviedo, p. 7-9.

(2002): El protocolo en España ayer y hoy. Discurso de apertura de en el acto solemne del curso académico 2002-2003. Facultad de Comunicación. Universidad de Sevilla.

MARTÍNEZ SÁNCHEZ, M.C. (2008): El protocolo como herramienta estratégica de comunicación. Una constante histórica y estudio de casos actuales. Tesis no publicada. Universidad de Sevilla

MONTEAGUDO ROBLEDO, M.P. (1995): "Fiesta y poder. Aportaciones historiográficas al estudio de las ceremonias políticas en su desarrollo histórico". Pedralbes, Revista D'Historia Moderna, (15), p. 173-205.

NIETO SORIA, J. M. (1999): "La realeza”. En Nieto Soria, José Manuel (director) (Ed.), Orígenes de la monarquía hispánica: Propaganda y legitimación, 14001520 Madrid: Dykinson, p. 25-62.

(2003): "Tiempos y lugares de la «realeza sagrada» en la Castilla de los siglos XII al XV". Annexes Des Cahiers De Linguistique Et De Civilisation Hispaniques Médiévales, (15), p. 263-284. Disponible en: http://goo.gl/aWNbvP [28/08/2013] (2007): "El poder real como representación en la monarquía castellano-leonesa del siglo XIII". Res Publica, (17), p. 81-104. Disponible en: http://goo.gl/KuC0ge [28/08/2013]

OTERO ALVARADO, M. T. (2009): Protocolo y organización de eventos. Barcelona: UOC

ORCÁSTEGUI Gros, C. (1995): “La coronación de los reyes de Aragón. Evolución político-ideológica y ritual". Instituto de Estudios Altoaragoneses, p. 633-648.

RAMOS FERNÁNDEZ, F. (2003): "El protocolo en la historia. Clases de protocolo. El protocolo social y el protocolo institucional”. En F. Ramos Fernández (Ed.), Curso superior de comunicación y protocolo. Pontevedra, Vigo: Universidad de Vigo p. 64-94

(2010): "La aportación portuguesa al protocolo internacional: El marqués de Pombal". En F. Ramos Fernández (Ed.), Estudios de comunicación y protocolo (I). Pontevedra, Vigo: Universidad de Vigo p. 191-196.

RÍO BARREDO, M.J. del. (1998): "Felipe II y la configuración del sistema ceremonial de la monarquía católica". En J. Martínez Millán (Ed.), Felipe II (15271598): Europa y la monarquía católica Madrid: Parteluz, p. 677-704. (2000): Madrid, urbs regia. La capital ceremonial de la monarquía católica. Madrid: Marcial Pons, Ediciones de Historia

RODRÍGUEZ ENNES, L. (2003): “Apuntes históricos en torno a la evolución del protocolo desde la Roma imperial hasta finales del antiguo régimen, con alguna referencia a Galicia”. En F. Ramos Fernández (Ed.), Curso superior de comunicación y protocolo Pontevedra, Vigo: Extensión universitaria. Universidad de Vigo, p. 35-56. 
SÁNCHEZ GONZÁLEZ, M.D.M. (2012): "Cuestiones de ceremonial y protocolo en las Cortes de Cádiz". Actas del XIII Congreso Internacional de Protocolo. San Fernando, Cádiz. Disponible en: http://goo.gl/8B8Kk3 [28/08/2013].

VALDEÓN, J., PÉREZ, J., \& JULIÁ, S. (2008): Historia de España (4a ed.). Madrid: Espasa Calpe

\section{La autora}

Olga Casal Maceiras es licenciada en Geografía e Historia, máster en Investigación en Comunicación, especialista en Protocolo y Ceremonial y doctoranda en la Universidad de Vigo. Desarrolla su actividad profesional como consultora de protocolo, comunicación y organización de eventos, e imparte docencia en esta área de conocimiento en varias universidades. 